Lymphology 52 (2019) 92-102

\title{
FACTORS AFFECTING INTERPRETATION OF TISSUE DIELECTRIC CONSTANT (TDC) IN ASSESSING BREAST CANCER TREATMIENT RELATED LYMPHEDEMA (BCRL)
}

\author{
H.N. Mayrovitz, E. Arzanova, S. Somarriba, S. Eisa
}

College of Medical Sciences, Nova Southeastern University, Davie, Florida USA

\section{ABSTRACT}

Tissue dielectric constant (TDC) measurements are increasingly used as quantitative adjunctive tools to detect and assess lymphedema. Various factors affect measured TDC values that may impact clinical interpretations. Our goal was to investigate possible impacts of: 1) anterior vs. medial arm measures, 2) total body water (TBW\%) and arm fat percentages (AF\%), 3) measurement depth, and 4) skin firmness. In 40 healthy women (24.5 2.5 years), TDC was measured bilaterally on anterior forearm to $0.5,1.5,2.5$, and $5.0 \mathrm{~mm}$ depths using $a$ multiprobe device and on anterior and medial aspects using a compact device. TBW\% and AF\% were measured at $50 \mathrm{KHz}$ and skin firmness measured by skin indentation force (SIF). Results showed: 1) No statistically significant difference in TDC values between anterior and medial arm, 2) a moderate direct correlation between TDC and TBW\% $(r=0.512, p=0.001), 3)$ an inverse correlation between TDC and AF\% ( $r=-0.494, p<0.001)$ with correlations greatest at the deepest depth, and 4) a slight but statistically significant inverse correlation between TDC and SIF ( $r=$ $-0.354, p=0.001$ ). TDC values with compact vs. multiprobe were within $6 \%$ of each other with interarm (dominant/nondominant) ratios not significantly different. The findings provide a framework to help interpret TDC values among divergent conditions.

Keywords: lymphedema, body water, skin firmness, skin water, breast cancer, tissue dielectric constant, measuring lymphedema

Prior reports have indicated that tissue dielectric constant (TDC) measurements are of use in detecting (1-3), assessing treatment outcomes (4-11) and characterizing and tracking (12-14) breast cancer treatment related lymphedema (BCRL) and other forms of edema and lymphedema(15-17). The method is noninvasive and easily done by touching the skin with a probe for less than 10 seconds. However, other reports have indicated TDC values to depend on the body part being measured $(18,19)$ and even within the same body part, such as the arm, TDC values may depend on the arm area in which measurements are made $(12,20)$. Variations in skin thickness, composition or possibly eccrine gland density may play a role in such observed differences. Most reported arm measurements have been done on anterior forearms. However, some anecdotal observations suggest that the medial forearm is more likely to demonstrate early lymphedema. It is thus of potential clinical interest to determine the extent to which measurements made on the anterior forearm might differ from those made on the medial surface. One of the goals 
of this research was to investigate this issue.

Another confounder that may affect clinical interpretation of TDC values is a patient's body composition. Such factors include their body fat percentage (FAT\%) and total body water percentages (TBW\%). Some recent work suggests that if TDC is measured on anterior forearm to a single depth of $2.5 \mathrm{~mm}$, TDC values are marginally dependent on FAT\% (21). However, it is unclear if this applies to other depths since increasing measurement depths include greater amounts of low-water containing fat. It was thus hypothesized that TDC values would correlate with $\mathrm{TBW} \%$ with correlation strengths that depend on measurement depth. Further, since TBW\% is inversely related to FAT\% it follows that arms with greater fat percentage will have lower TDC values and that the strongest correlation would be at the deepest measurement depth. It was an additional goal of this research to test these hypotheses.

Another possible confounding factor is hand-dominance if TDC differences attributable to hand-dominance are substantial. It is known that there are interarm differences in transepidermal water loss (22) and lymphatic processes (23) but evaluation of TDC values of hand dorsum (24) and anterior forearm (25) found no significant difference in TDC values when measured to a single skin depth of about $2 \mathrm{~mm}$. However, since it not known if this holds true for other commonly used measurement depths ranging from $0.5 \mathrm{~mm}$ to $5.0 \mathrm{~mm}$ this study sought to include a reasonable proportion of persons who were left-hand dominant so as to have a more generalized result.

\section{METHODS}

\section{Subjects}

Forty women, recruited from $1^{\text {st }}$ and $2^{\text {nd }}$ year medical students and university staff, participated in this research study. Of these women, 25 were right-hand dominant $(\mathrm{RH})$ and 15 were left-hand dominant (LH). Their participation followed their reading and signing of a university Institutional Review Board approved informed consent (\#2017-333). Participation required that they be self-reported healthy with no current or recent skin issues on either arm and not be ambidextrous.

Prior to including potential subjects, each was asked to complete a 10-question handedness classification form (26,27). Accordingly, potential subjects answered questions regarding which hand they use to perform certain activities. Example questions included which hand they would draw with or which hand they would hold the hammer if striking a nail or which hand they would use to stir their coffee. If they chose the right hand, a score of +1 was assigned, if they chose the left hand then a score of -1 was assigned. If they chose no clear preference (both), then a score of 0 was assigned. The range of composite scores is from -10 (extreme left handedness) to $+\mathbf{1 0}$ (extreme right handedness). A volunteer was considered as LH if their composite score was less than -4 and $\mathrm{RH}$ if their composite score was greater than +4 . For the present group, scores ranged from -8 to -10 for $\mathrm{LH}$ and from +8 to +10 for $\mathrm{RH}$.

Average subject age (mean $\pm \mathrm{SD})$ was $24.5 \pm 2.5$ years. Their body mass index (BMI) was $22.8 \pm 4.2 \mathrm{Kg} / \mathrm{m}^{2}\left(16.9\right.$ to $\left.37.3 \mathrm{Kg} / \mathrm{m}^{2}\right)$. According to current classification standards three subjects would be obese (BMI $\geq 30 \mathrm{Kg}$ / $\mathrm{m}^{2}$ ), six overweight (BMI of $2529.9 \mathrm{Kg} / \mathrm{m}^{2}$ ), 26 as normal (BMI of 18.5 to $24.9 \mathrm{Kg} / \mathrm{m}^{2}$ ) and five as underweight $\left(\mathrm{BMI}<18.5 \mathrm{Kg} / \mathrm{m}^{2}\right)$. Measurements were done in a dedicated experimental room with a room temperature of $22.5 \pm 1.0^{\circ} \mathrm{C}$ and relative humidity of $52.8 \pm 3.3 \%$.

\section{Initial Procedures and Measurements}

Subjects were seated in a comfortable chair with their arms resting in front of them on a pillow that was used for support and comfort. A site on their anterior forearm located $5 \mathrm{~cm}$ distal to the antecubital fossa was marked with a dot on both arms. These would be target sites for all anterior forearm measurements. In addition, a site on both medial forearms, also $5 \mathrm{~cm}$ distal to the antecubital 
fossa was marked. This would be the target site for medial TDC measurements. Thereafter, skin temperature (noncontact infrared thermometer, Exergen, Model DX501-RS, Watertown MA, USA) and circumference (Gulick type tape measure with calibrated tension, Model 67019, Country Technology Inc., Gays Mills, WI, USA) of the target sites was measured.

\section{Tissue Dielectric Constant (TDC) Measurements}

TDC was then measured with two different devices, both made by Delfin Technologies, Kuopio, Finland. The first measurement set was done using a multiprobe device (MMD) that has four separate probes with diameters of 10, 20, 23 and $55 \mathrm{~mm}$ that were used to measure to effective measurement depths of $0.5 \mathrm{~mm}, 1.5 \mathrm{~mm}, 2.5 \mathrm{~mm}$ and $5.0 \mathrm{~mm}$. The order of measurement was $2.5 \mathrm{~mm}$ to $5.0 \mathrm{~mm}$ to $0.5 \mathrm{~mm}$ to $1.5 \mathrm{~mm}$. This order was chosen to minimize probe switching time. Effective measurement depth is defined as the depth at which the excitation field is diminished to $1 / \mathrm{e}$ of its value. Measurements were made on anterior forearms $5 \mathrm{~cm}$ distal to the antecubital fossa. The other device is referred to as the compact device (MMDC) that is self-contained hand-held enclosure with a contact diameter $20 \mathrm{~mm}$. The compact TDC measurements were made after the multiprobe measurements, first on anterior forearms at the same site as the multiprobe measurements and then medial forearms also located $5 \mathrm{~cm}$ from the antecubital fossa but about $90^{\circ}$ rotated from anterior sites.

All arm measurements were in triplicate and were done bilaterally with subjects comfortably seated. The average of the triplicate measurements was then calculated and used. Each measurement was achieved by touching the probe to the skin with gentle but firm pressure for about five seconds. The dielectric constant or relative permittivity is a dimensionless number equal to the ratio of tissue permittivity to vacuum permittivity. For reference the dielectric constant of distilled water at $32^{\circ} \mathrm{C}$ is approximately 76. Because TDC values mainly depend on tissue water they provide quantitative indices of skin water content. Since TDC is measured at $300 \mathrm{MHz}$, its value is sensitive to both free and bound water (28). Inclusion of the bound water contribution is important since up to $80-90 \%$ of young adult skin water content is bound (29).

Both devices used work on the same principle. A very low power $300 \mathrm{MHz}$ signal is generated and transmitted into the skin via the coaxial probe that acts as an open-ended coaxial transmission line (30). Part of the signal is absorbed, mainly by tissue water, and part is reflected back to a either a control unit in the case of the multiprobe device or directly into the hand-held compact device. Based on the transmitted and reflected signal a complex reflection coefficient is calculated $(31,32)$ from which the dielectric constant is determined (33). Reflections depend on the complex permittivity of the tissue which in turn depend on signal frequency and the dielectric constant (the real part of the complex permittivity) and the conductivity of the tissue with which the probe is in contact. At $300 \mathrm{MHz}$, conductivity contributes little to the overall permittivity value and TDC is mainly determined by free and bound water molecules. Further details including prior uses for skin assessments, validation and repeatability data are described in the literature (34-37). Each probe is calibrated against various ethanol-water mixture concentrations each of known dielectric constant values (38).

\section{Skin Firmness via Indentation Force}

Following the TDC measurements, skin firmness was measured. This was done by measuring the skin indentation force (SIF) in milliNewtons $(\mathrm{mN})$ required to indent skin by $1.3 \mathrm{~mm}$ using a hand held battery-operated device (SkinFibroMeter, Delfin Technologies, Kuopio Finland). In use, skin is lightly touched whereupon a small indenter approximately $2 \mathrm{~mm}$ in diameter is caused to deform 
skin inwardly with the resultant force recorded and displayed on a window on the front of the device. Each device is equipped with internal sensors that accept measurements only within prescribed limits of force and velocity. Thus, if an applied force is too large or applied too slowly or too rapidly the software contained within the device prompts the user to repeat the measurement until it is within proper limits. A single recorded value is obtained as the average of five acceptable sequential measurements made rapidly in succession that takes about 5 seconds at a single site. Measurements were made in triplicate at the anterior forearm sites used for TDC measurements. Further details regarding device accuracy and uses may be found in recent literature (39-41).

\section{Grip Strength}

Grip strength (in pounds) was then measured to estimate forearm muscle development in dominant and nondominant arms as potential covariates. Subjects squeezed a digital hand dynamometer (Trailite, Germany, Digital Dynamometer, Amazon.com) three times, alternating between dominant and nondominant hands, with the average of the three tries used to assess grip strength of each arm. The dynamometer displayed the maximum achievable grip strength value for each try to assesses maximum isometric grip strength (42).

\section{Total Body Water (TBW\%) and Arm Fat (AF\%) Percentages}

After all arm measurements, subjects, removed their foot wear and stood on a scale for about 10 seconds while gripping a handleelectrode to measure their weight and body composition parameters using bioimpedance measurements at $50 \mathrm{KHz}$ (InnerScan Body Composition Monitor, Tanita model BC558). Primary parameters measured were total body water percentages (TBW\%) and dominant and nondominant arm fat percentages (AF\%). Values were determined by device proprietary algorithms based on the measured impedances.
Analysis

Prior to primary analyses parameter values were tested for normality. This included tests (Shapiro-Wilk) for all measured arm average values $(\mathrm{N}=40)$ and $\mathrm{TBW} \%$ and $\mathrm{AF} \%(\mathrm{~N}$ $=40)$. Except for the girth parameter $(\mathrm{p}=0.015)$ no other parameter was rejected as being normally distributed $(p>0.05)$. Assessment of relationships between TDC and TBW\% or AF\% and between TDC and SIF was tested using linear regression analysis. Comparisons between dominant and nondominant arms $(\mathrm{N}=40)$ were done using paired T-tests. Comparisons of parameters between right handers $(\mathrm{N}=25)$ and left-handers $(\mathrm{N}=15)$ and for those subjects below and above the median TBW\% ( $N=20$ each sub-group) was done using nonparametric analyses for independent samples (Mann-Whitney U Test). All statistical tests were done with SPSS V16. Unless otherwise stated results are presented as mean $\pm \mathrm{SD}$.

\section{RESULTS}

\section{Interarm and Right vs. Left Hand Dominance}

Table 1 compares parameter values measured on dominant and nondominant arms for the entire group of $\mathbf{4 0}$ women and also for averages of right and left arms for subjects who were right-hand dominant vs. left-hand dominant. Inter-arm differences were small and not statistically significant $(p>0.05)$ except for forearm girth and grip strength that were both greater for the dominant $\operatorname{arm}(\mathrm{p}<0.01)$. Right-hander parameters did not differ from left-hander parameters except that right handers showed a greater indentation force $(\mathrm{p}=\mathbf{0 . 0 3 5})$.

\section{Forearm TDC Values: Anterior vs. Medial}

TDC values measured with the compact device on anterior and medial aspects of both arms of the 40 subjects ( $n=80$ arms) were similar with no significant difference between these sites. Values for anterior vs. medial sites 
TABLE 1

Inter-Arm Parameter Comparisons

\begin{tabular}{|l|l|l|l|l|}
\hline Parameter & \multicolumn{1}{|c|}{$\begin{array}{c}\text { Dominant } \\
(\mathbf{D O M})\end{array}$} & $\begin{array}{c}\text { Non-Dominant } \\
(\text { NDOM) }\end{array}$ & $\begin{array}{c}\text { Right-handers } \\
\text { Average of } \\
\text { sides }\end{array}$ & $\begin{array}{c}\text { Left-handers } \\
\text { Average of } \\
\text { sides }\end{array}$ \\
\hline Skin Temperature $\left({ }^{\circ} \mathrm{C}\right)$ & $31.8 \pm 1.1$ & $31.6 \pm 1.5$ & $31.8 \pm 1.2$ & $31.6 \pm 1.0$ \\
\hline Forearm Girth (cm) & $22.4 \pm 2.5^{* *}$ & $22.2 \pm 2.4$ & $22.7 \pm 2.8$ & $21.7 \pm 1.3$ \\
\hline Grip Strength & $48.6 \pm 11.8 * *$ & $45.9 \pm 11.0$ & $48.6 \pm 13.3$ & $45.1 \pm 5.2$ \\
\hline Indentation Force (mN) & $45.4 \pm 14.6$ & $45.5 \pm 13.8$ & $48.8 \pm 13.0^{*}$ & $40.0 \pm 11.8$ \\
\hline TDC (Multiprobe) & \multicolumn{5}{|l}{} \\
\hline 0.5 mm depth & $31.5 \pm 3.0$ & $31.3 \pm 3.3$ & $31.3 \pm 2.8$ & $31.6 \pm 3.6$ \\
\hline 1.5 mm depth & $32.8 \pm 3.6$ & $32.5 \pm 3.7$ & $33.0 \pm 3.1$ & $32.2 \pm 4.2$ \\
\hline 2.5 mm depth & $26.1 \pm 2.9$ & $26.2 \pm 3.0$ & $25.7 \pm 3.3$ & $26.6 \pm 2.4$ \\
\hline 5.0 mm depth & $23.5 \pm 3.8$ & $24.2 \pm 4.3$ & $23.5 \pm 3.9$ & $24.5 \pm 4.2$ \\
\hline TDC compact - anterior & $27.8 \pm 3.2$ & $27.7 \pm 3.1$ & $27.5 \pm 3.2$ & $28.1 \pm 2.7$ \\
\hline TDC compact - medial & $27.9 \pm 3.0$ & $27.5 \pm 3.3$ & $27.6 \pm 3.3$ & $27.8 \pm 2.7$ \\
\hline
\end{tabular}

Table entries are mean \pm SD for dominant (DOM) and non-dominant (NDOM) measurements (columns 2 and 3) and for side averages of right-handers and left-handers (columns 4 and 5). Interarm differences were not statistically significant except for forearm girth and grip strength with ** corresponding to $\mathrm{p}<\mathbf{0 . 0 1}$. Right-hander parameters did not differ from left-hander parameters except for a greater indentation force for observed for right-handers $(* \mathrm{p}=\mathbf{0 . 0 3 5})$.

were $27.7 \pm 3.11$ vs. $27.7 \pm 3.15, \mathrm{p}=0.920$. Anterior forearm TDC values measured with the multiprobe device to depths of $1.5 \mathrm{~mm}$ and 2.5 mm were $32.7 \pm 3.6$ vs. $26.1 \pm 3.0, p<0.001$. Although TDC values measured with the compact device were close to those measured by the multiprobe at $2.5 \mathrm{~mm}$ depth, the compact values were statistically greater $(27.7 \pm 3.11$ vs. $26.1 \pm 3.0, p<0.001$ ) with overall compact/ multiprobe ratio of $1.060 \pm 0.053$. However, when considering inter-arm ratios (dominant/ non-dominant) measured with multiprobe or compact respectively, the TDC ratios were close with no significant statistical difference $(0.997 \pm 0.072$ vs. $1.007 \pm 0.061, p=0.25)$.

\section{TDC Relationship to Total Body Water and Arm Fat Percentages}

TDC values had a moderate positive correlation with total body water percentage (TBW\%) and an inverse relationship to arm fat percentage (AF\%) as shown in Figs. 1 and 2 for TDC measurement depths of $0.5 \mathrm{~mm}$ and $5.0 \mathrm{~mm}$. It may be noted that the slopes and correlation coefficients are greater for the deeper measurement depth. For clarity, the figures only include the least and greatest measurement depths, but there was in fact a trend for slopes and coefficients to increase from a least value measured at $0.5 \mathrm{~mm}$ depth to the greatest value measured for the $\mathbf{5 . 0}$ 


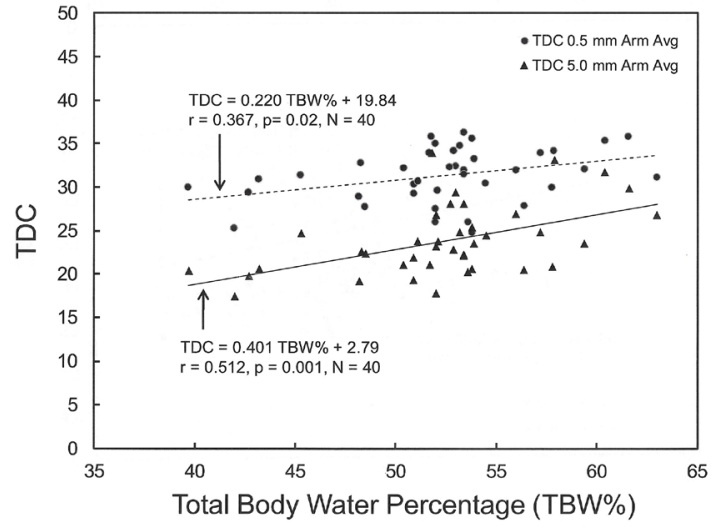

Fig. 1. TDC relationship to body water percentage. Data points are TDC values averaged between dominant and nondominant arms. Regression equations are for TDC measurements to a depth of $0.5 \mathrm{~mm}$ (circles, dashed line) and a depth of $5.0 \mathrm{~mm}$ (triangles, solid line). Correlation coefficient $(r)$ is greater for the deeper TDC measurement but both are statistically significant.

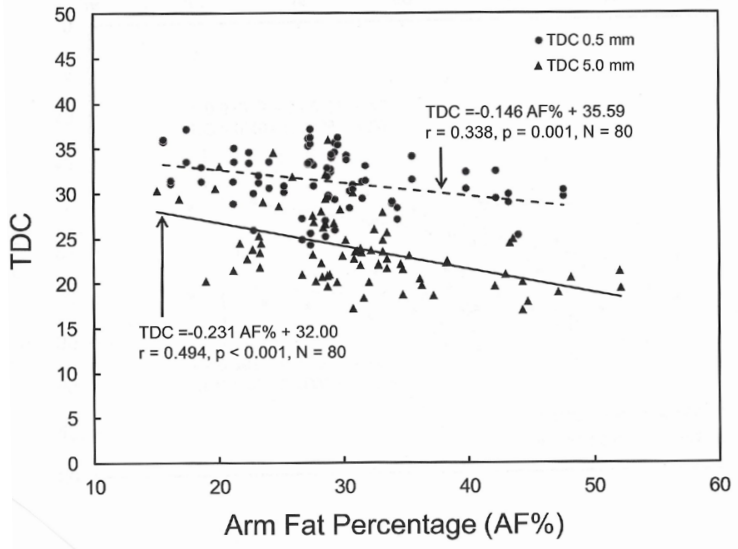

Fig. 2. TDC relationship to arm fat percentage. Data points are TDC values for each arm $(N=80)$. Regression equations are for TDC measurements to a depth of $0.5 \mathrm{~mm}$ (circles, dashed line) and a depth of 5.0 mm (triangles, solid line). Correlation coefficient (r) is greater for the deeper TDC measurement but both are statistically significant.

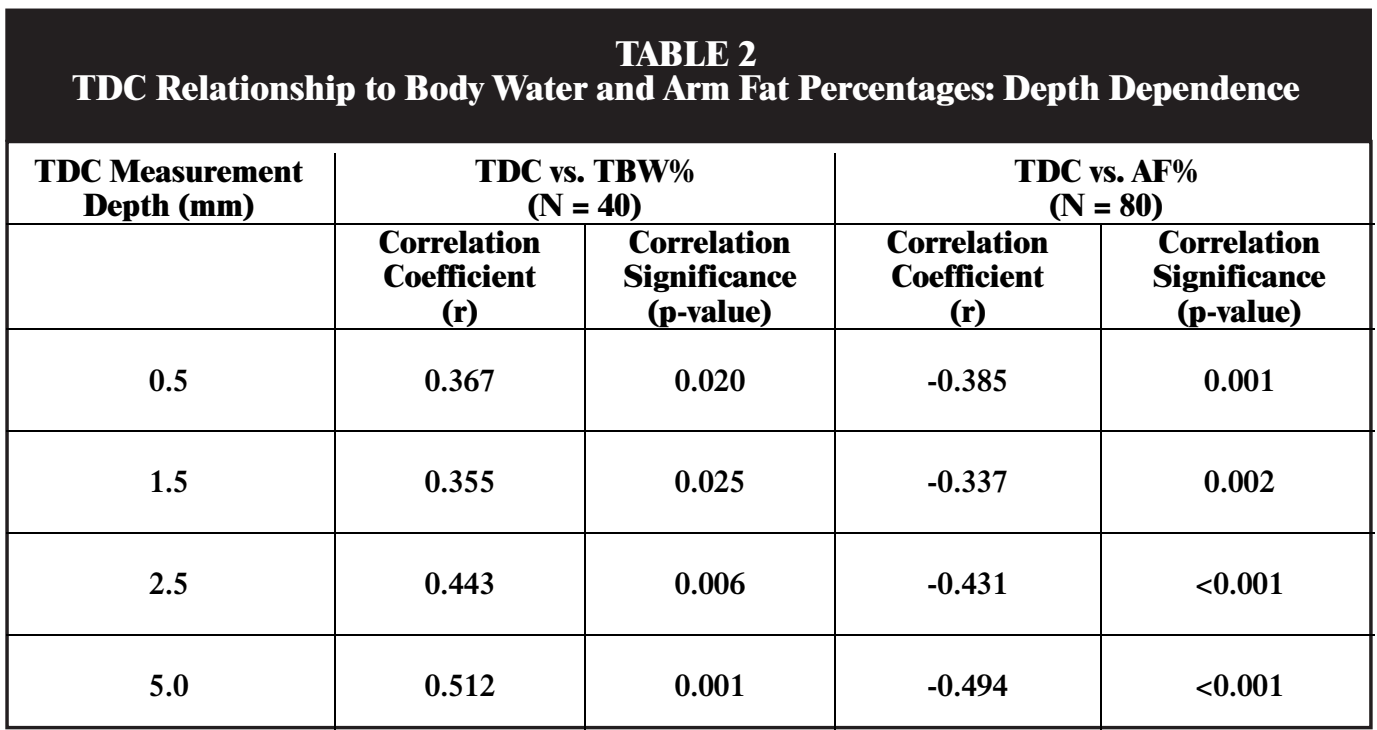

Impact of total body water percentage (TBW\%) and arm fat percentage (AF\%) on TDC depends on the depth at which TDC is measured. With increasing measurement depth, the correlation tends to increase from the shallowest depth $(0.5 \mathrm{~mm})$ to the deepest depth $(5 \mathrm{~mm})$. 
TABLE 3

TDC Dependence on Body Water Percentage (TBW\%)

\begin{tabular}{|r|c|c|}
\hline \multicolumn{2}{|c|}{ Total Body Water Percent (TBW\%) } \\
\hline \multicolumn{2}{|c|}{$<53 \%(\mathrm{~N}=\mathbf{2 0})$} & $>=53 \%(\mathbf{N}=\mathbf{2 0})$ \\
\hline TDC (Multiprobe) & $30.6 \pm 2.9$ & $32.2 \pm 3.1$ \\
\hline $1.5 \mathrm{~mm}$ depth & $31.5 \pm 3.6$ & $33.8 \pm 3.2$ \\
\hline 2.5 mm depth & $24.9 \pm 2.9$ & $27.3 \pm 2.6^{*}$ \\
\hline 5.0 mm depth & $22.5 \pm 3.8$ & $25.2 \pm 3.8^{*}$ \\
\hline TDC compact - anterior & $26.9 \pm 2.8$ & $28.6 \pm 3.0$ \\
\hline TDC compact - medial & $26.8 \pm 2.9$ & $28.6 \pm 3.1$ \\
\hline
\end{tabular}

Table entries are TDC values for women with TBW\% < median value $(53 \%)$ and $>=$ than $53 \%$. Mean values at all depths tended to be greater for the sub-group with the larger total body water percentage. Differences at $2.5 \mathrm{~mm}$ and $5.0 \mathrm{~mm}$ depths were statistically significant $(*=\mathrm{p}<0.05$ Mann-Whitney test).

mm depth. Table 2 summarizes these findings. When TDC values are compared between subjects above and below the median TBW\% (53\%) as in Table 3, mean values of TDC at all depths tended to be greater for the subgroup with the larger total body water percentage. Sub group differences at $2.5 \mathrm{~mm}$ and $5.0 \mathrm{~mm}$ depths were statistically significant $(\mathrm{p}<0.05$ Mann-Whitney test).

\section{TDC Relationship to Skin Indentation Features}

TDC values at all measurement depths were inversely related to skin indentation force (SIF). Increased SIF values serve as an index of increased skin stiffness. All correlations were statistically significant but with modest correlation coefficients. The strongest correlation between TDC and SIF was for a measurement depth of $1.5 \mathrm{~mm}$. At this depth the linear regression equation was TDC $=-\mathbf{0 . 0 9 0} \times \mathrm{SIF}+$

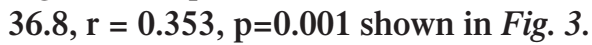

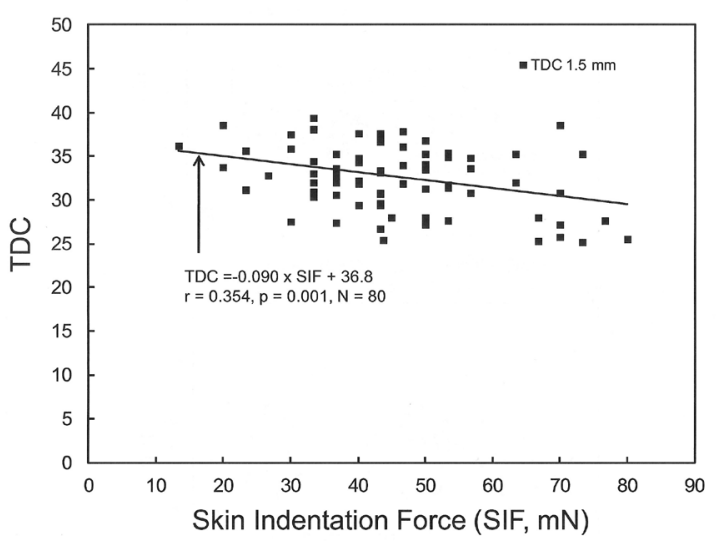

Fig. 3. TDC relationship to skin firmness. Data points are TDC values for each arm $(N=80)$. Regression equation is for TDC measurements to a depth of 1.5 $\mathrm{mm}$. The skin indentation force (SIF) is an index of skin firmness. 


\section{DISCUSSION}

Because of the increasing use of TDC measurements as a quantitative measure of lymphedema either singly or more commonly as a complementary assessment tool (4-7, 17,43-51), it is important to consider factors that may impact interpretation of clinical measurements. Herein we report on several factors that may have the potential to affect TDC values.

With respect to the question of anterior vs. medial forearm as a target measuring site, the present findings have demonstrated that in healthy non-edematous arms the TDC values obtained are very similar at these two anatomical sites with no statistically significant differences between them. The significance of this finding is that it provides confidence that, at least from a measurement standpoint, either of the sites can be used without having to consider any significant confounding influences attributable to location.

With respect to measurement device or measurement depth, the present findings are consistent with a previous report (52) in which the compact device was reported to yield values close to but slightly greater than those measured at a depth of $2.5 \mathrm{~mm}$ using the multiprobe system. These prior measurements, made on the anterior forearm of 32 young women, yielded compact TDC values on average 5.6\% greater than those measured to a depth of $2.5 \mathrm{~mm}$ which is close to the average herein obtained of $6.0 \%$. The significance of this finding is that under conditions in which absolute TDC values are compared in clinical or other uses, measuring devices are best not mixed between compact and multiprobe. However, if inter-side ratios and not absolute values are of interest, then this cautionary statement is not applicable as the ratios determined by both devices were similar.

With respect to the impact of a person's body water or arm fat percentages, the present findings demonstrate a clear relationship albeit only a moderate one. The general finding is that TDC values tend to increase with increasing total body water percentage and with decreasing arm fat percentages. The initial underlying hypothesis that such dependencies would be most evident when the TDC measurement depth was greater is supported by the larger correlation coefficients and significance levels obtained for the deeper as opposed to the shallower measurement depths. One significance of this finding is that it is possible to use the regression equations to estimate the likely change in TDC value that could be attributable to either a patient's gain or loss in total body water percentage or arm fat percentage when tracking or treating patients with BCRL. For the greatest body water change effect (measurement to a $5.0 \mathrm{~mm}$ depth) the regression slope (Fig. 1) is 0.401 indicating that it would take a 5\% change in total body water to cause a change of 2 TDC units. Measurements to all lessor depths would cause smaller changes in measured TDC values. These body water and fat effects and considerations are relevant when absolute TDC values are of interest. The findings may also suggest that it may be worthwhile considering the inclusion of simple measurements of patient's body composition parameters when evaluating or treating.

With respect to a possible linkage of skin stiffness to TDC values, the present findings indicate a small inverse relationship that appears to be greatest when measuring to a depth of $1.5 \mathrm{~mm}$ (Fig. 3). For this measurement depth the regression equation predicts a decrease of 0.09 TDC units for each $\mathrm{mN}$ increase in skin indentation force. In part the significance of this is that it would seem to predict that when following a patient or seeing a patient with increased skin stiffness through fibrosis, a decrease in TDC may be observed that is not related to an improvement in the condition. Although the amount of this effect appears to be small within the range of the healthy subjects herein studied, the full effect on patients in the later stages of lymphedema with increased skin stiffness in addition to underlying fibrotic changes is currently not known but is an area for future research. 


\section{CONCLUSION}

TDC values obtained noninvasively as indices of skin tissue water and its change in a variety of conditions has proved useful due to the method's biophysical underpinnings, its ease of use and the fact that it can be applied to skin of any external body part. However, interpretation of values so obtained depend upon knowledge of possible confounding factors that may affect them. The present results indicate no significant differences in forearm TDC values attributable to arm dominance or measurements made on anterior or medial surfaces. Contrastingly, TDC values tend to decrease with decreasing total body water percentage, increasing arm fat percentage and increasing skin stiffness. Although such TDC changes are not large, it is prudent to consider these factors when following patients in whom any of these parameters were to change significantly. The tabular data herein supplied can provide estimates for that purpose. Additionally, because of the clear impact of measurement depth on TDC values, sequential tracking of patient status, just chronologically or subsequent to treatment interventions, must use the same probe type to insure proper interpretation of changes. Finally, although not specifically considered in the present experimental data, sequential tracking values, especially over longer time-frames, are most accurately interpreted if changes in device sensitivity over time are periodically determined.

\section{CONFLICT OF INTEREST AND DISCLOSURE}

All authors declare no competing financial interests exist.

\section{REFERENCES}

1. Mayrovitz, HN, DN Weingrad, S Davey: Local tissue water in at-risk and contralateral forearms of women with and without breast cancer treatment related lymphedema. Lymphat. Res. Biol. 7 (2009), 153-158.
2. Mayrovitz, HN: Assessing local tissue edema in postmastectomy lymphedema. Lymphology 40 (2007), 87-94.

3. Mayrovitz, HN, DN Weingrad, S Davey: Tissue Dielectric Constant (TDC) measurements as a means of characterizing localized tissue water in arms of women with and without breast cancer treatment related lymphedema. Lymphology 47 (2014), 142-150.

4. Czerniec, SA, LC Ward, SL Kilbreath: Assessment of breast cancer-related lymphedema: A comparison of moisture meter and spot bioimpedance measurement. Lymphat. Res. Biol. 13 (2015), 10-19.

5. Donahue, PM, R Crescenzi, AO Scott, et al. Bilateral changes in deep tissue environment after manual lymphatic drainage in patients with breast cancer treatment-related lymphedema. Lymphat. Res. Biol. 15 (2017), 45-56.

6. Johansson, K, S Hayes, RM Speck, et al: Waterbased exercise for patients with chronic arm lymphedema: A randomized controlled pilot trial. Am. J. Phys. Med. Rehabil. 92 (2013), 312-319.

7. Koehler, LA, DW Hunter, AH Blaes, et al: Function, shoulder motion, pain, and lymphedema in breast cancer with and without axillary web syndrome: An 18-month follow-up. Phys. Ther. 98 (2018), 518-527.

8. Mayrovitz, HN: Assessing lymphedema by tissue indentation force and local tissue water. Lymphology 42 (2009), 88-98.

9. Mayrovitz, HN, S Davey: Changes in tissue water and indentation resistance of lymphedematous limbs accompanying low level laser therapy (LLLT) of fibrotic skin. Lymphology 44 (2011), 168-177.

10. Mayrovitz, HN, S Davey, E Shapiro: Localized tissue water changes accompanying one manual lymphatic drainage (MLD) therapy session assessed by changes in tissue dielectric constant inpatients with lower extremity lymphedema. Lymphology 41 (2008), 87-92.

11. Mazor, M, BJ Smoot, J Mastick, et al. Assessment of local tissue water in the arms and trunk of breast cancer survivors with and without upper extremity lymphoedema. Clin. Physiol. Funct. Imaging 39 (2019), 57-64.

12. Koehler, LA, HN Mayrovitz: Spatial and temporal variability of upper extremity edema measures after breast cancer surgery. Lymphat. Res. Biol. 17 (2019), 308-315.

13. Mayrovitz, HN, DN Weingrad, L Lopez: Patterns of temporal changes in tissue dielectric constant as indices of localized skin water changes in women treated for breast cancer: A pilot study. Lymphat. Res. Biol. 13 (2015), 20-32. 
14. Mayrovitz, HN, DN Weingrad: Tissue dielectric constant ratios as a method to characterize truncal lymphedema. Lymphology 51 (2018), 125-131.

15. Birkballe, S, MR Jensen, $S$ Noerregaard, et al: Can tissue dielectric constant measurement aid in differentiating lymphoedema from lipoedema in women with swollen legs? $\mathrm{Br}$. $\mathrm{J}$. Dermatol. 170 (2014), 96-102.

16. La Gioia, A, E Porter, I Merunka, et al: Open ended coaxial probe technique for dielectric measurement of biological tissues: Challenges and common practices. Diagnostics (Basel) 8 (2018), pii: E40. doi: 10.3390/diagnostics8020040.

17. Pigott, A, J Nixon, J Fleming, et al: Head and neck lymphedema management: Evaluation of a therapy program. Head Neck 40 (2018), 1131-1137.

18. Mayrovitz, HN, S Davey, E Shapiro: Local tissue water assessed by tissue dielectric constant: Anatomical site and depth dependence in women prior to breast cancer treatment-related surgery. Clin. Physiol. Funct. Imaging 28 (2008), 337-342.

19. Mayrovitz, HN, M Bernal, F Brlit, et al: Biophysical measures of skin tissue water: variations within and among anatomical sites and correlations between measures. Skin Res. Technol. 19 (2013), 47-54.

20. Mayrovitz, HN, M Luis: Spatial variations in forearm skin tissue dielectric constant. Skin Res. Technol. 16 (2010), 438-443.

21. Mayrovitz, HN: Impact of body fat and obesity on tissue dielectric constant (TDC) as a method to assess breast cancer treatment related lymphedema (BCRL). Lymphology 52 (2019), 18-24.

22. Treffel, P, F Panisset, B Faivre, et al: Hydration, transepidermal water loss, $\mathrm{pH}$ and skin surface parameters: Correlations and variations between dominant and non dominant forearms. Br. J. Dermatol. 130 (1994), 325-328.

23. Bourgeois, P, O Leduc, JP Belgrado, et al: Effect of lateralization and handedness on the function of the lymphatic system of the upper limbs. Lymphology 43 (2010), 78-84.

24. Mayrovitz, HN, E Arzanova, S Somarriba, et al: Reference values for assessing localized hand lymphedema using interhand tissue dielectric constant ratios. Lymphat. Res. Biol. 16 (2018), 442-445.

25. Mayrovitz, HN, M Fasen, P Spagna, et al: Role of handedness on forearm skin tissue dielectric constant (TDC) in relation to detection of early-stage breast cancer-related lymphedema. Clin. Physiol. Funct. Imaging 38 (2018), 670675.
26. Van Strien, JW: Classificatie van links- en rechtshandige proefpersonen [Classification of left- and right-handed research participants]. Nederlands Tijdschrift voor de Psychologie 47 (1992), 88-92.

27. Van Strien, JW: The Dutch handedness questionnaire. . URL: hdl.handle.net/1765/ 956, 2003.

28. Pennock, BE, HP Schwan: Further observations on the electrical properties of hemoglobin bound water. J. Phys. Chem. 73 (1969), 26002610.

29. Gniadecka, M, O Faurskov Nielsen, DH Christensen, et al: Structure of water, proteins, and lipids in intact human skin, hair, and nail. $\mathbf{J}$. Invest. Dermatol. 110 (1998), 393-398.

30. Stuchly, MA, TW Athey, GM Samaras, et al: Measurement of radio frequency permittivity of biological tissues with an open ended coaxial line: Part II - Experimental Results. IEEE Trans Microwave Theory and Techniques 30 (1982), 87-92.

31. Lahtinen, T, J Nuutinen, E Alanen: Dielectric properties of the skin. Phys. Med. Biol. 42 (1997), 1471-1472.

32. Lan, CC, HS Yu, SM Huang, et al: FK506 induces interleukin-6 secretion from UVB irradiated cultured human keratinocytes via p38 mitogen-activated protein kinase pathway: Implication on mechanisms of tacrolimus-induced skin irritation. J. Dermatol. Sci. 48 (2007), 225-228.

33. Alanen, E, T Lahtinen, J Nuutinen: Variational formulation of open-ended coaxial line in contact with layered biological medium. IEEE Trans Biomed Eng 45 (1998), 1241-1248.

34. Jensen, MR, S Birkballe, S Nørregaard, et al: Validity and interobserver agreement of lower extremity local tissue water measurements in healthy women using tissue dielectric constant. Clin. Physiol. Funct. Imaging 32 (2012), $317-$ 322.

35. Mayrovitz, HN, S Davey, E Shapiro: Suitability of single tissue dielectric constant measurements to assess local tissue water in normal and lymphedematous skin. Clin. Physiol. Funct. Imaging 29 (2009), 123-127.

36. Mayrovitz, HN, X Guo, M Salmon, et al: Forearm skin tissue dielectric constant measured at $300 \mathrm{MHz}$ : Effect of changes in skin vascular volume and blood flow. Clin. Physiol. Funct. Imaging 33 (2013), 55-61.

37. Nuutinen, J, R Ikaheimo, T Lahtinen: Validation of a new dielectric device to assess changes of tissue water in skin and subcutaneous fat. Physiol. Meas. 25 (2004), 447-454. 
38. Mayrovitz, HN: Assessing free and bound water in skin at $300 \mathrm{MHz}$ using tissue dielectric measurements with the MoistureMeterD. In: Lymphedema: Presentation, Diagnosis, and Treatment. Greene, AK, H Brorson, SA Slavin (Eds.), Springer, New York, pp 133-148, 2015.

39. Viren, T, JT Iivarinen, JK Sarin, et al: Accuracy and reliability of a hand held in vivo skin indentation device to assess skin elasticity. Int. J. Cosmet. Sci. 40 (2018), 135-140.

40. Mayrovitz, HN, J Wong, M Fasen: Age and hydration dependence of jowl and forearm skin firmness in young and mature women. $\mathbf{J}$ Cosmet Dermatol. 17 (2018), 1262-1270.

41. Mayrovitz, HN, K Corbitt, A Grammenos, et al: Skin indentation firmness and tissue dielectric constant assessed in face, neck, and arm skin of young healthy women. Skin Res. Technol. 23 (2017), 112-120.

42. Steele, J, K Raubold, W Kemmler, et al: The effects of 6 months of progressive high effort resistance training methods upon strength, body composition, function, and wellbeing of elderly adults. Biomed. Res. Int. 2017 (2017), 2541090.

43. Bakar, Y, A Tugral, U Uyeturk: Measurement of local tissue water in patients with breast cancer-related lymphedema. Lymphat. Res. Biol. 16 (2018), 160-164.

44. Fife, CE, S Davey, EA Maus, et al: A randomized controlled trial comparing two types of pneumatic compression for breast cancerrelated lymphedema treatment in the home. Support Care Cancer 20 (2012), 3279-3286.

45. Lahtinen T, J Seppala, T Viren, et al: Experimental and Analytical Comparisons of Tissue Dielectric Constant (TDC) and Bioimpedance Spectroscopy (BIS) in assessment of early arm lymphedema in breast cancer patients after axillary surgery and radiotherapy. Lymphat. Res. Biol. 13 (2015), 176-185.
46. Mayrovitz, HN: Assessing lower extremity lymphedema using upper and lower extremity tissue dielectric constant ratios: Method and normal reference values. Lymphat. Res. Biol. (2019) Jan 30. doi: 10.1089/lrb.2018.0039.

47. Mayrovitz, HN, JA Yzer: Local skin cooling as an aid to the management of patients with breast cancer related lymphedema and fibrosis of the arm or breast. Lymphology 50 (2017), 56-66.

48. Rockson SG. Detecting lymphedema: Bioimpedance spectroscopy and the tissue dielectric constant. Lymphat Res. Biol. 13 (2015), 169.

49. Suehiro, K, N Morikage, O Yamashita, et al: Distribution of extracellular fluid in legs with venous edema and lymphedema. Lymphat. Res. Biol. 14 (2016), 156-161.

50. Tugral, A, T Viren, Y Bakar: Tissue dielectric constant and circumference measurement in the follow-up of treatment-related changes in lower-limb lymphedema. Int. Angiol. 37 (2018), 26-31.

51. Zaleska, MT, WL Olszewski: The effectiveness of intermittent pneumatic compression in therapy of lymphedema of lower limbs: Methods of evaluation and results. Lymphat. Res. Biol. 17 (2019), 60-69.

52. Mayrovitz, HN, DN Weingrad, F Brlit, et al: Tissue dielectric constant (TDC) as an index of localized arm skin water: Differences between measuring probes and genders. Lymphology 48 (2015), 15-23.
Harvey N. Mayrovitz, PhD
College of Medical Sciences
Nova Southeastern University
3200 S. University Drive
Davie, FL 33328 USA
E-Mail: mayrovit@nova.edu 